\title{
Alrededor del Amor y de la Muerte en la Poesía Medioeval.
}

Antes de entrar al tema mismo del amor y de la muerte clentro de la literatura de la Edad Media es preciso fijar, a grandes rasgos, las características culturales del Medioevo, motivo ya de múltiples y frondosos trabajos, pero que es necesario redondear en sistematizado plan de conocimiento. Extremos ataques e intencionadas defensas se han llevado a cabo alrededor de ese período de la historia, que constituye algo así como el alba đel mundo europeo. Ya Schlegel, decia hace un sigle lo siguiente:

"Represéntase a menuco la Edâd Media como una laguna en la historia del espiritu humano; como un espacio vacío entre la civilización de la Antigüedad y las luces de los tiempos modernos. Por una parte se hacen perecer enteramente las artes y las ciencias para hacerlas luego salir de improviso de la nada, después de una noche de io siglos y con un brillo admirable; pero esto es, bajo dos aspectos, falso, parcial y erróneo. Jamás ha perecido enteramente lo esencial de la civilización y de los conocimientos de la antigïedad y por el contrario la mayor parte de cuanto han producido los tiempos modernos de bello y grande tiene su origen en la Edad Media y en su espiritu'. 
Sin ponernos de acuerdo con la opinión del conocido tratadista -opinión que ha sido muly repetida desde entonces con ánimo de exaltar el Medioevo- debemos considerar la importancia cultural de aquella etapa en la que si, por una parte, se quiebra el mundo romano, por otra se gesta el mundo de occidente, la cultura fáustica que diría Spengler. Schlegel partía del concepto falso, y ya completamente rebatido, de que la cultura era aquella linea que venía hacia nosotros desde el comienzo del mundo y que satisfaciendo el orgulio de los europeos orientaría la tesis de "progreso" en las concejciones positivistas de Compte. La Edad Media no es una laguna, ni un paréntesis, pero tampoco se puede afirmar que lo que hoy constatamos como obra de belleza y de superación dentro de los siglos modernos, ha nacido precisamente en la Edad Media comonecesario hilo conductor del pasado al presente. Constituye una época de destrucción y nueva conjunción de-fuerzas; iñ̌fańcia de la cultura europea; momento de recolección de tradiciones venidas por muchos y variados caminos, como los tiempos prehoméricos para la cultura de Grecia. Todo estuvo en proceso de forma-

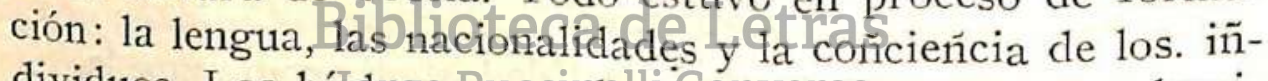
dividuos. Los bátbagros queildeldiruyerons Roma y que dominaron Bizancio traían un muńdo reñovado de capameñto, de dioses y un nuevo álito que infundieron a las formaciones culturales de Europa Y la religión surgida de la predicación cristiana derrotó, a st1 vez, al espíritu pagano, insurgiendo el extraño aspecto de la vida ultraterrana y la aspiración de la muerte como liberación y como triunfo final, superviviendo, tan solo, la esencia de la latinidad como herencia y legado de proporciones imprecisables. Tres corrientes han unido su cauce. En los conventos y monasterios, en las cortes de los grandes señores - representativos de la economía feudal en marcha; antiguos capitanes bárbaros, sal- 
teadores de ciudades y jefes de banda-se habla el latín hasta muy avanzada la Edad Media y se manifiesta que fué el vehículo de la cultura de la antigüedad. Sin embargo los Humanistas, los que adentraron a fines del medioevo, en el exacto conocimiento de la literatura y el arte greco-latinos y provocaron el llamado "Risorgimiento" estuvieron dentro del "romance" y produjeron en él. No puede negarse, empero, que el acopio romano está latente en el habla de las diversas poblaciones que, ex-provincias romanas, se van apartando muy lentamente del tronco común, mantenieñdo un nexo por sobre las migraciones y por sobre la fuerza telúrica que los iba diferenciando. Abadias y universidades conservan - a veces sigilosamente- ricos tesoros de las viejas culturas. Los Monasterios de Garrow, de York, las Universidades de Bolonia, de Oxford, de Palencia, de Salamanca mantienen ei culto de la latinidad. E1Reino de los Cielos, base fundamental del cristianismo, constituye, en calidad de segundo elemento formador, un nuevo horizonte en las creeñcias humanas de Europa. La muerte pareció, desde entonces, más lógica, más natural pero mas hondamente conmovedora. De esa aspiración, de ese-ntevo espirfitu, de esas inquietud me-

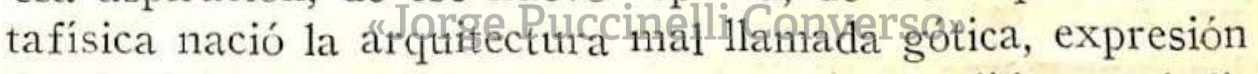
del inclividuo medioeval. con las puntas tendidas al infinito y como negación del concepto espacial de la vida, con raíces en la tierra y afán de más allá. Y como tercera base "culturizadora" están los pueblos bárbaros con costumbres, Derecho y tradiciones que se sedimentan en los cuatro costados del Viejo Continente. Un mundo feudal vaciado en las reglas "Caballerescas"; el "amor a la Dama" de estirpe germánica y los motivos selváticos de la religión de Odín, son vivos y elocuentes testimonios de esa influencia. Desde entonces han de surgir en la literatura: las encinas y los fresnos sagrados; los tilos mágicos y las grandes fogatas 
que ahuyentan los genios malos del bosque. Cantos de combate y amor tienen su origen en las tiendas de campaña de Teodorico, de Hermann y de Atila, incoporado a la germania.

En este especial momento de renovación y de surgimiento, las ideas de la muerte y del amor van a adquirir los especiales contornos que Europa ha recogiclo en su literatura. Manifiestamente distintas a las concepciones que sobre esas dos fuentes inagotables de arte tuvieron los hombres de Roma y de Grecia. Para ello contribuyeron no solamente las aportaciones cristianas y bárbaras, sino que también de Oriente llegaron con los barcos de los aventureros y de los comerciantes en Asia y en los restos expedicionarios de los Cruzados, los estremecimientos místicos y los refinamientos sensuales. Arabia y Persiarse hicieron presentes en Provenza.

De esa Provenza, donde indudablemente se asimiló algo de la lírica oriental, salieron los trovadores con sus cantos de amor. Como los aedas helénicos iban de corte en corte, cantando ante los señores y en el corrillo asombrado de los habitantes deB pyrgo tEera noentonaban gestas nacionales; no ensalzaban da acciónidelsus çterreros, ni se referían a los fundadores de su nacionalidad; ellos entonaban sus notas de confidencia; hablaban de sí mismos, de la mujer amada y de la primavera. Pero en ellos el amor se confundía con la muerte El amor era siempre una aspiración para el más allá. La mujer no era sino un ideal inalcanzable dentro de este mundo; aquí; en este lado de la vida; por eso el amor venía a suspirar por la muerte, donde se confundirían los amantes en la presencia de la felicidad eterna. Rudel enamorado de Melisandra por lo que de ella hablan los peregrinos que han pasado por Trípoli, sólo encuentra a la amada en el momento de morir: punto de enlace, meta acaricia- 
da, estremecimiento apetecido en larga estancia sobre la vida; así sea en las ricas tierras de Langüedoc. Un solo instante la Canción de Rolando nos lleva a la presencia del amor; es el momento en que Auda cae muerta a los pies de Carlomagno ante la noticia del sacrificio heróico de Roldán.

$\mathrm{Ni}$ Tíbulo que amó idealmente a Delia, que representó la ternura y la veneración por la mujer amada en Roma, pudo concebir este amar en la muerte; esta regocijada esperanza de un amor que encuentra su horizonte eñ lo que está fuera del alcance de los sentidos. Dante inmortaliza a Beatriz como el amor santo, como la gracia misma que ha de conducir a la felicidad eterna; nunca Durante Alighieri pensó en alcanzar terrenalmente a Beatriz; y Petrarca que vivía en Aviñón tan cerca de Laura, tampoco la quiso para sí; ella alimentó los sonetos del "Cancionero" y fué tema central en la alegoría de los "Trionfi"; su muerte dió motivo a aquellos sentidos versos que ha inmortalizado la crítica. Pero Petrarca, como el Dante, amaba a Laura en la muerte, la quería en la muerte; la deseaba más allá de lo terreno, de lo transitorio, de lo perecedero. Es éste el "alto amor", el "hohe minne" del Caballero Von der VogebvåideeNa el aniog talapé de los tilos, junto a los matorrales conplas flotes tronchadas bajo la hierba, que constituye el "niedere minne".

También la Europa medioeval tuvo sus primeras entonaciones líricas en las festividades religiosas, en la cosechas, en el trabajo del hilado, pero la fuerte correntada que procedente de las cálidas zonas de 'Arabia, inundó Provenza y la Península Ibérica y más tarde se esparció al Continente, impuso el tema del amor y los serventesios, los tensós y los torneos trataron de inmortalizar a la dama, inmortalizando 
al caballero. Los "chansons d' amour" después de vivificar en el melodioso y rítmico dialecto de "oc" habían de pasar a la zona walona, más tarde a las regiones alemanas y también a Italia, donde primero se hicieron "soneto" en Sicilia, con la influencia del Ministro de Vignas y "canzzone" en Toscana con el maestro Guinicelli, el filósofo escéptico Guido Cavalcanti y tantos otros, hasta llegar a la belleza formal del "Cancionero" de Petrarca.

Amor sumiso, esclavo; amor por la "única", la que siempre estará lejos. Y así se llegó, a la vuelta del camino, a una poesía artificiosa, cortesana, aduladora, en los famosos "Puy". La nota confidencial se convirtió en motivo de concurso y se forjó una literatura basada en falsos sentimientos, en postura, en convencionalismos ajenos a la fuente primaria de la pasión puesta en juego. Así se multiplicaron los nombres de los trovadores en el sur de Francia y más tarde se llegó a la almibarada poemática "primaveral" de Carlos de Orleans.

Dentro de la épica surgía, asimismo, la dominante obsesión caballeresca. Lancelote dispuesto a los caprichos de la reina Ginebra; Tristan ê Isolda solo fleles a su amor, por encima de tơâtgotra efreunstancia, mâs allá del filtro. Cretien de Troyes nos dió una serie de personajes imbuídos de la ley de la caballería. El amor de los caballeros está reflejado en sus obras que responden a la más notable producción de la épica cortesana del ciclo céltico. La tesis del amor por sobre toda consideración nos la da Erec al castigar a Enida que sabrestimó el "que dirán". La admiración por el triunfo está presente en el "Caballero de León", donde la Dama de la Fuente se enamora del matador de su propio esposo precisamente por la hazaña cumplida. Pero, ante todo, se nos aparece en el "Caballero de la Carreta". Lancelote es 
el tipo, el prototipo del amante. Su valor y su nombre están al servicio de la Reina Ginebra, antes que al del Rey Arturo. $Y$ en aquella escena romántica, al pié de la habitación de la reina, junto al viejo muro, Lancelote espera dócilmente que ella apruebe o desapruebe la rotura de las rejas que impiden el encuentro. El poema de Cretien termina cuando Ginebra accede.

Cuando los alemanes toman para sí los motivos de la épica cortesana francesa, trasplantan el contenido del amor caballeresco: Enrique de Valdeke no altera en lo menor el espíritu de los troveros arturianos. Tal vez si en el "Gregorio" de Hartmann podemos descubrir diverso carácter al crearnos el problema de Edipo dentro de un honorable caballero cristiano. Por otra parte Wolfram de Eschembach reacciona contra la "fácil moralidad" de la poesía cortesana; Laudina, la Dama de la Fuente le parece aborrecible por su repentino amor por Iwain y orgullosamente nos ofrece un Parsifal convicto; un Parsifal perseverante en la fé y que mantiene el culto del amor matrimonial.

La poesía popular germánica nacida de las viejas sagas entremezcladas en el correr de los años, añejo vino madurado por los poetas trashumantes y por los campesinos que recitaban las tradiciones a pleno sol, ha de exhibirnos - con caracteres eminentemente trágicos- la pasión amorosa de Crimilda y su venganza sangrienta, definitiva, por la muerte de Sigfrido. Son estas notas diferentes a las anteriormente presentadas. Hay la fuerza pagana, la influencia de las diosas fluviales del Rhin y la glorificación de personajes que como Teodorico, Atila, están muy distantes de la cultura cristiana en todos sus aspectos. Luchas de caracteres, exaltación de la pasión: he ahí los móviles de "Los Nibelungos", completamente ajenos al amor artificioso y al 
ideal feudal caballeresco que preside generalmente la poesía medioeval.

La muerte tenía para los hombres de la 'Antigüedad características de término. Sueño de bronce la llama Homero. En la Odisea, la muerte está vivamente representada en el viaje que hace al Aides el prudente Ulises y sus compañeros de fatigas a indicación de la Maga Circe. Sombras tristes que suspiran por la vida. Inexistencia corporal absoluta como lo prueban los fallidos intentos de Ulises por abrazar a su madre. La muerte estaba más allá de los sentidos y de las aspiraciones. Para los romanos significaba también un definitivo separarse de lo amado y lo querido. $Y$ aunque el viaje de Eneas nos muestra ya una diferencia entre este otro mundo y el de los griegos: ya que aquí los Campos Eliseos constituyen un triunfo post-morten, síi embargo el pensamiento de la latinidad se detiene en lo que está de este lado. Premios y felicidades recibidas de los dioses se obtienen acá y cuarido elibseabandenareha de venir la muerte como llegó para el gaterosenkelenamorado Turno.

La creencia judaica de la felicidad en la otra vida, fortalecida por la concepción del Reino de los Cielos que el Rabí de Galilea profetizara para los elegidos, llevaron a nuevas sensaciones y pensamientos con respecto a la muerte y los nuevos cantos épicos señalan como triunfadores a los que la han obtenido por su Dios. Ya el poeta romano Aurelio Prudencio compone Odas en honor de los mártires: "Las Coronas" y "El Libro de los Himnos", paganizando el cristianismo al decir de Renán, y abriendo surcos en la poemática religiosa. Más tarde han de ser Tertuliano o Juan Mosch los que relieven la personalidad de los mártires, in- 
citando a morir, porque la muerte es esperanza, porque allá está la verdadera vida. Y Severino Boecio, Ministro de Teociorico y más tarde decapitado por orden suya, en la prisión de Pavía y ante la inminencia de su condena, escribe las magníficas e inspiradas páginas "De Consolatione", doride la filosofía surge ante él para anunciarle la futilidad de la vida terrestre y la felicidad suprema de la presencia de Dios. La melancólica obra de Boecio es una puerta abierta a las nuevas coìcepcionies de la muerte eń el campo literario.

En su confluencia con la poesía del amor, esta nueva visión llevó a la consagración de esa especial categoría del amor en la muerte, que entraña un proceso integralmente medioeval. La vida no es más que un corto camino. El mismo del peregrinaje que lleva a los trovadores y a los juglares, a través de los pueblos de Europa, con la canción en la boca, como aquel anciano Timoffei en Ta poesía de Rilcke.

Dante fué un constante poeta de la muerte. Como lo sostiene Papini, desde los comienzos de la "Vita Nouva" se cbserva un deseo, velado es cierto, de que Beatriz muera; de que se conviertaiblaspiecrónte Inetivede eternidad.

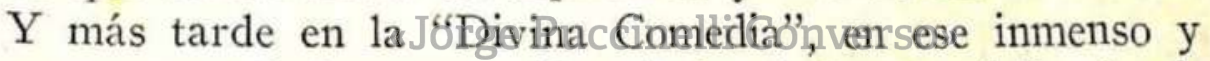
gran poema de la muerte, Beatriz ha de llegar, visión de ultratumba, para conducir al poeta a la felicidad misma; fuera de todo lo terreno, más allá de la pasión y del deseo.

Petrarca ha recogido, asimismo, las enseñanzas de los provenzales en materia que señalamos. El lo declara, cuando dice que: "Venía luego un tropel de gente extranjera; era el primero de todos Arnaldo Daniel, gran maestro diel amor". Así llegaron las raíces de la lírica de "oc" hasta la tierra siciliana y toscana con estos nuevos mundos descubiertos en el choque de varias culturas. Y Petrarca inmortalizó a Laura muerta y creó para ella la alegoría de los 
"Trionfi", con el definitivo triunfo de la eternidad sobre el tiempo, vencedor a su vez de la muerte, y sedimentando esa aspiración de más allá que caracteriza a toda esta larga etapa del Medioevo.

Sinembargo aquella alentadora noción del amor en la muerte, que significa la exaltación de la misma, ha de hallar fin en un poeta profundamente humano, hecho de tierra y sentimiento, que con sensibilidad también medioeval, va a presentarnos la visión descarnada de la muerte. Poeta fanfarrón y aventurero, Francisco Villón representa un momento singular de la poesía en los estertores de la Edad Media. Hijo de aldeanos, embadurnado con la vida de un París que ya representaba bohemia, Villón el poeta de los condenados a muerte y de las estrofas vigorosas; el primer poeta de Francia, como se le ha llamado, compone en "La Balada de las Damas de "Antaño" su concepción de la muerte en plano realista; en fuertes pinceladas de sudor, de espasmo, de agonía. Hasta aquí se había balanceado la muerte, pero con él caía a peso, enterrando en la nada a la reina Blanca que era "como una flor de lis que cantaba con voz de sirena" y a tantas otras princesas y damas des categoría. Por encima de sus fechorias, Villón representa el punto más alto en la lírica medioeval, en esta su forma de tratar la muerte, como lo hiciera en España, nuestro siempre citado Jorge Manrique. Cantor de bodegón y de taberna, cierra en Francia un período y se abre con él la correntada de humanismo que lleva al "Risorgimiento". Con inspiración honda, dice Claretié, cantó el reinado incontrastable de la muerte, pero ya como peso supremo, como definitiva piedra sepulcral eí la vida del hombre, sin esperanzada felicidad en el otro lado, en el más allá. 